International Journal of Child, Youth and Family Studies (2017) 8(1): 74-96

DOI: http://dx.doi.org/10.18357/ijcyfs82201716754

\title{
ETHICS IN CHILD AND YOUTH CARE PRACTICE WITH TRANSGENDER YOUTH
}

\section{Beth A. Clark}

\begin{abstract}
Issues that arise in child and youth care practice with transgender (trans) youth and their families can be complex and ethically challenging. While many trans youth are thriving and have strong family and social supports, others face family conflict and experience negative health outcomes linked to societal stigma. The purpose of this paper is to explore how four ethical approaches - bioethics, rights-based ethics, relational ethics, and justice-doing — may be applied to practice situations involving trans youth and their families. This paper is grounded in the gender affirmative model of care and integrates empirical evidence, critical thinking, and explicit argumentation in ethical analysis. Following a brief overview of evidence related to trans youth care, case vignettes are analyzed using diverse ethical approaches. These approaches draw on a variety of philosophical and disciplinary traditions. However, the analyses consistently lead to three imperatives: providing support and affirmation for trans youth; supporting families to support their youth; and fighting injustice where it impedes these goals.
\end{abstract}

Keywords: transgender, adolescents, youth, ethics, child and youth care, bioethics, social services

Beth A. Clark, MM, RCC, is a counsellor, educator, and Interdisciplinary Studies PhD candidate at the University of British Columbia, Vancouver, BC Canada.

Email: beth.clark@alumni.ubc.ca 
Transgender (trans) youth have long been served by the child and youth care (CYC) profession. However, due to increasing visibility of trans youth, expanding options for health care, and a growing body of research, the time has come to consider ethical issues that can arise in practice. Trans youth come from all cultural and socioeconomic backgrounds and many have high levels of family and social support. Others lack family support or access to gender affirming health care providers at crucial times in their lives. Some youth will access gender affirming health care, while others will not. Regardless of their path, trans youth and families can benefit from the support of knowledgeable care providers throughout their journeys.

Issues that arise in CYC practice with trans youth and their families can be complex and ethically challenging, and may involve family conflict or rejection, youth suicidality, religious beliefs, and the potential benefits and harms of providing or withholding gender affirming medical care. This paper is grounded in the gender affirmative model of care and written from the perspective that the integration of sound evidence, critical thinking, and explicit argumentation are key in addressing ethically challenging practice issues.

In this paper, the term trans is used to include anyone whose gender does not align with the sex they were assigned at birth. While this term may not fit every instance, it is intended to be inclusive of people with binary (e.g., transwoman, transman) and non-binary (e.g., genderqueer, genderfluid) genders. Cisgender describes people whose gender matches the sex they were assigned at birth. Gender affirming medical care refers to medical treatment (e.g., puberty suppression, hormone therapy) that supports physical characteristics congruent with one's gender, while social affirmation/transition refers to non-medical options for presenting oneself in a manner that aligns with one's gender (e.g., name, pronouns, clothing; Provincial Health Services Authority, 2016).

The purpose of this paper is to explore how four ethical approaches - bioethics, rightsbased ethics, relational ethics, and justice-doing — may be applied to practice situations involving trans youth and their families. While it is not possible to provide an exhaustive summary of ethical approaches or practice situations, this paper is intended to offer the reader contrasting perspectives that may be employed in working through ethically challenging situations. This paper is focused on the CYC profession; however, the information presented may be applied in other disciplines, such as social work, counselling, and education. It is hoped that this discussion will stimulate critical thinking about the role of CYC workers in ensuring access to needed services and fostering strong family relationships, as well as providing direct support, information, and advocacy for trans youth and their families. 
International Journal of Child, Youth and Family Studies (2017) 8(1): 74-96

\section{Background}

\section{Medical}

Hormonal changes associated with puberty are responsible for the development of secondary sex characteristics. Breast growth, menstruation, changing voice, and facial hair growth are examples of pubertal changes that can cause significant distress if they are incongruent with a youth's gender. Gender affirming medical care interventions available for youth include pubertal suppression and hormone therapy (de Vries \& Cohen-Kettenis, 2012). Pubertal suppression is a fully reversible intervention that blocks the sex hormones that the body naturally produces in order to temporarily stop secondary sex characteristic development, while hormone therapy is a partially reversible intervention through which hormones that produce desired secondary sex characteristics are provided (de Vries et al., 2014; Khatchadourian, Amed, \& Metzger, 2014). Some youth go on to have gender affirming surgeries, typically once they reach the age of majority (Coleman et al., 2012).

\section{Psychosocial}

Current research paints a complicated picture of transgender youth, with documented high rates of suicidality, self-harm, mental health issues, and substance use coupled with lower rates of school success, employment, and family acceptance (Ryan, Russell, Huebner, Diaz, \& Sanchez, 2010; Travers et al., 2012; Veale et al., 2015). However, recent studies have also highlighted the crucial roles of family support and gender affirming medical care in the overall wellbeing of trans youth (Bernal \& Coolhart, 2012; de Vries et al., 2014; Khatchadourian, Amed, \& Metzger, 2014; Olson, Forbes, \& Belzer, 2011; Ryan et al., 2010). In one recent study, trans youth who had access to pubertal suppression and hormone therapy, and who went on to have gender affirming surgery as young adults, reported psychosocial outcomes very similar to their cisgender peers (de Vries et al., 2014). Research also has shown that trans youth with higher levels of parent support and family connectedness report more positive self-esteem, mental health, and life satisfaction than those with lower levels (Travers et al., 2012; Veale et al., 2015).

\section{Safety}

Safety is a major concern when working with trans youth, given the high rates of harassment and violence faced in schools and in the community (Veale et al., 2015; Herman, 2013; Taylor \& Peter, 2011). In a 2013-2014 Canadian survey, 55\% of trans youth aged 14-18 reported being bullied in school in the last year, $64 \%$ taunted or ridiculed, and $36 \%$ physically threatened or injured, while 70\% experienced verbal sexual harassment, and 37\% physical sexual harassment (Veale et al., 2015). Many schools develop policies that address the unique needs of trans youth, such as using correct names and pronouns in classrooms and on school records, supporting gender and sexuality alliances, and ensuring access to washrooms and change rooms (British Columbia Teachers’ Federation, 2016; Vancouver School Board, 2014; Wells, Roberts, \& Allan, 2012). 
International Journal of Child, Youth and Family Studies (2017) 8(1): 74-96

\section{Ethical issues}

The medical, counselling, and ethics literature pertaining to trans youth care has primarily focused on issues related to endocrine care and has cited bioethics principles: autonomy, beneficence, non-maleficence, and justice. Issues of autonomy include youth rights to privacy and confidentiality, arbitrary age requirements to access care, and emerging capacity to consent to care (Giordano, 2007, 2013; Milrod, 2014; Stein, 2012; Swann \& Herbert, 2009). Benefits of endocrine care include relieving psychological suffering and preventing the development of unwanted secondary sex characteristics, which, coupled with the low risk of harm from this treatment and the potential risk of causing harm by withholding care, make a compelling case in support of endocrine care for trans youth (Antommaria, 2014; Baltieri et al., 2009; Giordano, 2007; Holman \& Goldberg, 2006; Stein, 2012; Vrouenraets et al., 2015). Some have questioned whether youth possess the maturity necessary to make decisions about endocrine care, especially given the lack of data on long-term outcomes and potential impacts on future fertility (de Vries et al., 2006; Vrouenraets et al., 2015); however, many have concluded that youth do, as in other areas of health care, have the capacity to make these decisions (Holman \& Goldberg, 2006; Giordano, 2007; Kreukels \& Cohen-Kettenis, 2011). Finally, systemic barriers that negatively impact access to gender affirming medical care for trans youth have been cited as issues of justice in the ethics literature (Giordano, 2007).

\section{Role of practitioners}

Ethical dilemmas for practitioners can arise in situations involving trans youth for a variety of reasons, which may or may not be gender-related; however, this paper focuses specifically on issues related to trans identities and expressions. For example, care providers may struggle with how best to support a young person whose decisions related to gender identity or expression do not have parental support. It is also important to recognize that some people hold beliefs that they feel are not compatible with recognizing trans identities as valid.

Bernal and Coolhart (2012) highlighted considerations for family therapists working with transgender youth and their families, placing emphasis on the ethical role of the family therapist. They set forth guidelines that include: providing accurate information and education to youth and families; connecting youth and families with community resources in order to reduce isolation; and acting as an advocate for clients. Other suggestions for practice with trans youth and families involve recognizing that there is a diversity of healthy genders, respecting autonomy, providing an informed consent process, balancing benefits and risks, and delivering equitable services (Giordano, 2007, 2013; Holman \& Goldberg, 2006; Roen, 2016; Stein, 2012; Vrouenraets et al., 2015).

Swann and Herbert (2009) recommended that social workers practicing with trans youth pay careful attention to their own biases and belief systems. Regardless of the degree of personal and professional experience and expertise with trans communities, practitioner awareness of how personal and professional values and assumptions impact decision-making is essential for strong 
International Journal of Child, Youth and Family Studies (2017) 8(1): 74-96

ethical practice. Use of established ethical approaches can support critical thinking about salient issues and affected parties, including the beliefs and values of the practitioner encountering an ethical dilemma. Conversely, a lack of critical thinking can lead to practices that may not be in the best interest of youth and families (Heath, 2012). Osmo and Landau (2001) proposed that explicit argumentation - articulating the justification for making a decision — is a necessary element in ethical decision-making.

\section{Theoretical approach}

Current understandings of gender identities and expression are arguably incomplete; however, an emerging body of literature provides theoretical foundations and empirical evidence on which to base practices with trans youth and their families. Historically, three approaches to care or treatment with children and youth have been recognized: (a) psychotherapy, to change gender to be congruent with sex; (b) watchful waiting, which includes supporting a person while delaying a decision about gender affirmation or transition until adulthood; and (c) the gender affirmative model, in which an individual is supported to live in and freely express their gender (Ehrensaft, 2016; Swann \& Herbert, 2009). The first two models are not well-supported by clinical evidence. Attempting to change gender to be congruent with sex (e.g., reparative or conversion therapy) is an approach currently considered harmful and unethical to practice (Canadian Association of Social Workers \& Canadian Association of Social Work Educators, 2015; Coleman et al., 2012) and it has been outlawed in multiple jurisdictions (CBC News, 2015; New York State, 2016). Watchful waiting and withholding gender affirming medical care during adolescence are not considered to be neutral acts, but rather interventions that can have negative consequences for youth due to psychological distress and development of irreversible secondary sex characteristics (Coleman et al., 2012).

The gender affirmative model is an approach to care in which practitioners seek to understand what a child or youth is communicating about their gender, emphasizing that there are many healthy ways to experience and express gender and that children and youth have the developmental capacity to understand their own gender (Ehrensaft, 2016; Hidalgo et al., 2013). A key concept in the gender affirmative model is that of gender health, "defined as the opportunity for children to live in the gender that feels most real and/or comfortable” (Ehrensaft, 2016, p. 16). Research findings have indicated that children who are supported to live in their authentic gender before puberty exhibit mental health similar to their cisgender peers (Olson, 2016). As mentioned earlier, youth who have access to gender affirming medical care and parental support also have more positive mental health outcomes. While some people raise concerns that youth may change their minds about their gender, research has indicated that it is highly unlikely for youth who have an increase in the intensity of gender dysphoria when they start puberty to desist later in adolescence (Kreukels \& Cohen-Kettenis, 2011). Given the theoretical and empirical support for this approach to care, the analyses in this paper are grounded in the gender affirmative model for trans youth and their families. 
International Journal of Child, Youth and Family Studies (2017) 8(1): 74-96

\section{Methods}

This paper presents a case-based approach to exploring ethics in practice, which is consistent with medical ethics education (Diekema, Mercurio, \& Adam, 2001). Each analysis begins with a brief overview of one of four ethical approaches: bioethics, rights-based ethics, relational ethics, and justice-doing, followed by a fictionalized vignette involving a CYC practitioner and a trans youth. An ethical dilemma emerging from the vignette is summarized, then analyzed in accordance with the established framework. The analysis is grounded in empirical evidence and critical thinking, leading to an explicit statement of how a practitioner may resolve the dilemma.

\section{Analyses}

\section{Bioethics}

Overview. Bioethics has roots that can be traced back to Hippocrates (Peel, 2005) and the imperative to "do no harm". Contemporary bioethics has four foundational principles: autonomy, non-maleficence, beneficence, and justice (Peel, 2005). The following overview of these principles is based on the work of Beauchamp and Childress (2013), who provided a comprehensive exploration of these principles in health care. Respect for autonomy means that competent persons can "act intentionally, with understanding, and without controlling influences that determine their action” (Beauchamp \& Childress, 2013, p. 104). This may mean engaging in informed consent processes so people fully understand their options, allowing choice in care, and ensuring decisions are made free from coercion. Non-maleficence describes the duty to do no harm, and also to prevent and remove harm. Beneficence (sometimes combined with non-maleficence) mandates that care providers work to benefit the client, or to "do good". Finally, the principle of justice calls on practitioners to recognize inequities in health care access and health status, and work toward fair, equitable, and appropriate treatment for everyone (Beauchamp \& Childress, 2013).

Mac (age 15) has been living at a group home for a couple of months and is fairly comfortable talking with Andrea, a CYC worker. Mac says she doesn't mind living at the group home too much, but is hoping to reunite with her mother and stepfather soon. Part of Andrea's job is to document her discussions with Mac about her parents, as the team works toward reunification. One afternoon, Mac comes home from school visibly upset. Andrea asks if she wants to talk and Mac shares that some girls regularly give her a hard time about looking like a guy and she is tired of dealing with it. Andrea asks what they have done, and Mac describes mostly verbal harassment, but says sometimes one of the girls shoves her up against the lockers and threatens to beat her up.

Mac continues, saying that the reason it bothers her so much is because she doesn't really feel like a girl or a guy, and is questioning whether she might be trans. She talked with a school counsellor once who gave her some resources about non-binary 
genders and social supports, but she has not told anyone else. Mac says she wants to continue presenting as a girl at the group home (e.g., using female pronouns). She is very afraid of what her parents might say, and doesn't want to do anything that might mess up her plan to return home. Looking frightened, Mac asks Andrea not to tell anyone about their conversation.

Dilemma. Mac has entrusted Andrea with very personal information that she does not want shared. However, Andrea is responsible for documenting what Mac tells her so that it can be used when the team works with the family. Andrea is mindful of the potential for this disclosure to impact discharge planning for Mac, for example, if her parents were to learn this information and react negatively. However, there is also a possibility that the parents will find out about Mac's gender at a later time, resulting in Mac being at risk after reunification, when the team is not in place to provide support. Andrea is also aware that Mac is exploring her identity and expressing uncertainty about her gender at this time.

Analysis. Autonomy is the first principle Andrea will apply from a bioethics framework. First, Mac has previously demonstrated maturity in making a broad range of decisions. If she is to be allowed choice in care, Andrea should respect Mac's decision about whether and when to discuss her gender with her parents, and Mac has clearly declared that she does not want this information shared. She was placed in the group home by a government agency temporarily providing guardianship. Mac was informed of the policies of the program (specifically regarding information sharing among team members), but she was not given a choice about placements. Therefore, Andrea questions whether Mac was truly able to give informed consent to these policies. This situates Mac's autonomy at odds with an agency policy that she has not freely agreed to. Andrea contemplates trying to convince Mac that she should share this information with her parents, but recognizes that this would be coercive and violate Mac's autonomy.

Non-maleficence means that Andrea has a duty to do no harm, and also to prevent and remove harm. In this situation, failing to disclose this information to the team and to Mac's parents could be harmful in the long term. If Mac's parents learn about her gender after reunification, without resources in place to support the family, Mac could be at risk for family rejection, and even homelessness or violence. If Andrea discloses this information in the short term, plans for reunification could be permanently terminated, which would be emotionally harmful to Mac and to her parents. The issue of harm from bullying at school also needs to be addressed, as Mac is regularly experiencing verbal and physical harassment.

The principle of beneficence guides Andrea in the direction of acting in ways that will benefit her client. Reunification is Mac's goal and keeping her trans status confidential is her request. From Mac's perspective, this is what is good for her. This could also be beneficial for Mac's parents who would continue planning for reunification and working on strengthening their lifelong relationships with Mac. Keeping confidence and working toward reunification does not preclude disclosure of this information later on in the process, when Mac and her parents have a 
stronger relationship and still have supports in place to help them navigate this experience. Additionally, Andrea considers that she could address the issue of gender-based bullying focusing on the students' inappropriate behavior — without disclosing Mac's gender.

Lastly, justice must be taken into account. Andrea has recognized some of the health inequities faced by trans youth in her consideration of Mac's situation. When experiencing family rejection, trans youth are at greater risk for homelessness, violence, and compromised mental and physical health. Residential care and other health institutions are often not well prepared to provide affirming care for trans youth. Andrea realizes she should examine how her institution could improve their services in order to provide all trans youth with a safer environment while in care. It is also important to look beyond the bounds of this institution, to the broader community, to learn about existing supports for trans youth and families, and possibly to advocate for additional services.

Resolution. Andrea's primary concern is supporting the wellbeing of Mac and her family, and her deliberation is informed by research documenting the importance of family support in the lives of trans youth. When considering all four of these principles, Andrea decides that ensuring the disclosed information is not shared with Mac's parents is important for Mac's autonomy, for avoiding immediate harms, and for promoting immediate and long-term benefits. However, Andrea is concerned about the long-term implications for family relationships and the lack of supports both in the group home and in the larger community to which Mac will be discharged. Andrea therefore works with her supervisor and team to document the information - in keeping with agency policies - with an agreement that it will not be shared with the family until such time as Mac is ready. The team can now be mindful of creating an environment that is more supportive of gender diversity. In working with the family, team members can focus on strengthening relationships and having supports in place for Mac to come out to her parents in the future, if she decides to do so. In the short term, Andrea offers to help Mac report the bullying at school, supports her in exploring her gender, connects her with community resources, and reassures her that she can choose whether and when to talk with her parents about her gender.

\section{Rights-based ethics}

Overview. Rights-based ethics are rooted in the idea that some rights are inherently a part of being human and that as beneficiaries of these rights, humans bear a responsibility to not infringe the rights of others (Peel, 2005). This approach to ethics is grounded in health and human rights agreements, such as those established by the United Nations and the World Health Organization (WHO).

The Constitution of the WHO (2006) proclaimed that "the enjoyment of the highest attainable standard of health is one of the fundamental rights of every human being” (p. 1) and that "healthy development of the child is of basic importance" (p. 1). The United Nations Convention on the Rights of the Child (United Nations General Assembly, 1989) declared that the following rights, among others, pertain to all children under the age of majority: the right to have their best 
interests given primary consideration; the right to access information to promote wellbeing; and the right to be protected from abuse and neglect. The Convention on the Rights of the Child also established the right of parents to provide direction and guidance to their child "in a manner consistent with the evolving capacities of the child", as well as freedom of religion, with the caveat that religious freedom may be limited in order to protect health or the "fundamental rights and freedoms of others". A human rights fact sheet issued by the Office of the United Nations High Commissioner for Human Rights (2008) further stated that "adolescents' right to health is ... dependent on health care that respects confidentiality and privacy and includes appropriate mental, sexual and reproductive health services and information” (p. 15).

While there is much documentation and discussion of these rights and their integration into high-level policy, it can be challenging to apply a rights-based framework on a practice level, especially when different rights are in conflict. London (2008) took up the issue of how individual health care workers interface with a rights-based approach, stating that even though health care workers have an obligation not to act in a discriminatory manner, individual workers can inadvertently become perpetrators of human rights violations. This may occur as they experience conflict surrounding dual loyalty to their clients and to the institutions for which they work (London, 2008). Critical thinking and reflection surrounding the obligations of practitioners and the rights of youth and families is therefore integral to working from a rights-based perspective.

Aiden (age 17) is referred to Tom, a school-based CYC worker. Aiden has come out as trans and wants support talking with his parents. Aiden's hope is that his parents will start using his chosen name and male pronouns, and support him in starting hormones. He has thought about using street hormones, but would rather get them prescribed by a doctor. After a few individual support sessions, Tom sets up a meeting with Aiden and his parents, which he thinks goes fairly well. The parents are visibly upset, but do not react in an overtly negative manner.

Two weeks later, Tom receives a call from Aiden's mom, asking to meet about her "daughter". In their meeting, Aiden's mother accuses Tom of planting ideas in her child's head and promoting gender transition. She wants Tom to stop meeting with Aiden and to promise that he will not provide any more information about trans resources. Aiden's mom said their church does not approve of people being gay or transgender, and they are dealing with things at home, as is their right.

Aiden, visibly distraught, comes to find Tom the next day, saying that his parents have threatened to send him to a religious school or kick him out if he does not start acting like a girl. Aiden does not share his parents' religious beliefs. He asks Tom for help talking to his parents again.

Dilemma. Tom is faced with a decision about whether to keep working with Aiden or to terminate services as his parents have requested. Tom has an established relationship as a support 
person for Aiden, who is in crisis and requesting support from Tom at this time. However, Aiden's mother is his legal guardian and has clearly stated that she feels she has a right to parent according to her religious beliefs. Tom will deliberate on rights related to health, access to health information and services, confidentiality and privacy, parents, religion, and the best interests of the youth.

Analysis. Tom first considers the right of a youth to access confidential and private health services and information, in particular those that relate to mental, sexual, and reproductive health. Tom has been confidentially providing these services and information, and this was only made known to the parents at the request of Aiden. Tom thinks it is unlikely that Aiden's parents will provide or allow access to the information and education necessary to ensure safe use of hormones. He knows that Aiden's health may be jeopardized if he resorts to using illegally obtained hormones. Tom thinks that withdrawing support and education would be a violation of the right to confidential health services and information.

At the centre of this dilemma are the conflicting beliefs of Aiden and his parents. Tom is concerned that he will be violating the rights of Aiden's parents to raise their child in accordance with their religious beliefs. However, the right to provide direction and guidance according to religious beliefs is not absolute according to the United Nations Convention on the Rights of the Child (United Nations General Assembly, 1989), meaning that this right can be limited if it impedes another's health, rights, or freedoms. In this case, it appears that Aiden's fundamental right to the highest attainable standard of health is in conflict with his parents' desire to prevent him from accessing necessary care.

Finally, attention is given to the right of youth to have their best interests given primary consideration. Tom is familiar with the evidence that access to gender affirming medical care and family support are important factors in trans youth wellbeing. By providing support, Tom would be respecting Aiden's views of what is best for him, while simultaneously placing his safety at home and family relationships in jeopardy. If Tom honours the parents' wishes, Aiden will probably not gain access to gender affirming medical care. While he may maintain safe housing and some level of support, Aiden will still not have the support of his family with regard to his gender, and he may experience negative psychosocial outcomes as a result of being denied access to the support and care he needs.

Resolution. After considering conflicting rights of youth and parents and evidence about psychosocial outcomes for trans youth without parental support, Tom decides that continuing to support Aiden is the best course of action. This will honour Aiden's established right to the highest attainable standards of health, access to health information and services, and confidentiality and privacy; his best interests will be given primary consideration. Providing confidential health information, education, and services is an essential role that Tom feels obligated to fulfill. While he does not want to violate the parents' right to their religious beliefs, Tom feels he has a responsibility to ensure Aiden has access to information and resources. However, because access to care in combination with parental support are shown to promote strong health outcomes, Tom 
International Journal of Child, Youth and Family Studies (2017) 8(1): 74-96

has a responsibility to ensure Aiden's parents are also supported. He will work with his supervisor and other community care providers to offer comprehensive supports for Aiden and his parents in order to promote strong family relationships while ensuring access to needed care.

\section{Relational ethics}

Overview. Relational ethics holds that ethics are inherent in every situation, interaction, and relationship, and that it is within these moral encounters that people decide what is the "right thing to do" for themselves and for others (Bergum, 2013). Relational ethics are found between care providers and their clients, and may also involve family members, other professionals, administrators, and politicians. This approach is framed not as a list of principles or virtues, but as a moral space created when people are in relationship with one another (Bergum, 2013). Within this approach, ethics are in action - embodied, interdependent, and connected (Pollard, 2015). This approach centres around the larger question of how we should live together, balancing interdependence with freedom, emotion with reason, and unique situations with universal human experiences (Austin, 2008).

Bergum (2013) presented four relational ethics themes intended to guide health care practices: environment, embodiment, mutual respect, and engagement. The environment includes all of us, as actors within the ecological systems that control access to many things, including health care resources. Embodiment refers to the understanding that clients have their own lived realities and attends to the connection of mind and body. Mutual respect describes ways to engage with one another in the presence of differences, be they of power, knowledge, beliefs, values, experiences, or attitudes; it requires openness to and respect for others' perspectives. Even in the face of time constraints, practitioners must be in the moment with their clients, engaging in ways that allow understanding of situations, perspectives, and vulnerabilities different from their own. Dialogue is seen as "the space wherein relational ethics is most easily realized" (Bergum, 2013, p. 18).

These relational themes were taken up by Pollard (2015) in the context of nursing practice. Pollard emphasized that the interaction itself informs the actions of the care provider. It is not a question of whether or not to engage, for engagement is fundamental. The goal is to identify the needs, talents, and capacities of the client through interaction, allowing greater understanding of the client's view. Pollard made it clear that this endeavour is distinct from imagining oneself in the client's shoes, but is an act that goes beyond the intellectual, to include affective, emotional, and cognitive engagement. For this to be achieved, people must be viewed as interdependent and connected through relationships, not as disembodied clients. Finally, according to Austin (2008), "It must be recognized that persons marginalized and/or stigmatized due to factors such as poverty, gender, and illness can be disadvantaged in serious ways” (p. 748).

Jade (age 15) is socially transitioning and is accepted by her friends. Her parents are tolerating her gender expression, but clearly view this as a phase of gender exploration. They do not use female pronouns or the name Jade at home. Jade has 
International Journal of Child, Youth and Family Studies (2017) 8(1): 74-96

been referred to Kris, who provides youth and family outreach through a community-based mental health agency. Jade tells Kris that she wants to take hormones and needs help getting to see a medical specialist because she has not been able to convince her parents that she is ready for hormone therapy. Her parents have said she needs to wait until she is an adult, and then she can decide for herself. They have clearly refused to give consent for hormone therapy.

Kris knows that starting hormone therapy is a big decision and understands the parents' desire for Jade to wait. However, he knows that as Jade progresses through puberty, the irreversible changes to her body are getting more distressing. Jade has talked about feeling suicidal, but expresses hope for the future - a future where she is able to start hormone therapy as soon as possible. Kris knows of a gender clinic where youth can access hormone therapy. He believes that Jade is capable of making health care decisions and knows that where she lives she legally has the right to do so. Gaining access to gender affirming medical care could alleviate a lot of distress. However, Kris is aware that referring Jade to the gender clinic against her parent's wishes may cause conflict and place Jade at risk within her home.

Dilemma. There are many competing issues that Kris must navigate, including Jade's capacity for decision-making, need for hormone therapy, distress around lack of access to care, suicidal ideation, and parents' lack of support. Kris must figure out whether to make a referral to the gender clinic, and how to work with Jade and her parents. Using a relational ethics approach, Kris seeks to determine the "right thing to do" in his relationships with Jade and her parents.

Analysis. In this case, an important aspect of the environment is how access to health care is controlled. Kris is an actor within this system, possessing the knowledge of who is able to provide hormone therapy for youth and the ability to facilitate access to providers. Kris recognizes that he has a great deal of power within his relationship with Jade and also within his relationship with her parents. He has shared some of his knowledge about gender affirming medical care with Jade, but realizes her parents may not have access to this same information.

Kris does not understand the experience of being trans first-hand. However, it is not his responsibility to imagine himself in Jade's situation, but rather to attempt to understand her embodied experience from her perspective. For Jade, her experience is one of wanting her body to be congruent with her gender, to embody her gender through development of secondary sex characteristics. This speaks to the relational ethics theme of embodiment, and the importance of bringing mind and body together. Kris believes Jade should be able to freely express her gender and pursue hormone therapy, but must examine how this belief influences his ability to be in relationship with Jade’s parents.

This brings Kris to the theme of mutual respect. He knows he must work to understand the lived experience of Jade's parents, who do not want to see her take any steps toward gender 
affirming medical care at this time. He must not only have respect for beliefs and values that differ from his own, but be truly open to the value and validity of these perspectives. Kris has engaged a great deal with Jade, to understand her perspective, strengths, and vulnerabilities, but feels he needs to engage further with Jade's parents.

Resolution. Kris's plan for moving ahead focuses foremost on respectful dialogue. Engaging in mutually respectful dialogue - acknowledging differences of power, knowledge, beliefs, values, experiences, and attitudes — will enable Kris to expand his understanding of this family's connection and conflict, and help all involved to move toward common ground. Remaining present and engaged will also help to sustain Kris in this process. In order to support Jade, Kris seeks to engage in a manner that promotes mutual respect, understanding, and the safest and healthiest relationships possible among Jade, her parents, and himself. Through ensuring that the family's environment includes access to care, information, and support, and that Jade's voice is heard regarding the distress she is experiencing surrounding her gender and embodied experience, Kris anticipates that family relationships will be strengthened, a shared understanding will emerge, and Jade will ultimately experience improved wellbeing.

\section{Justice-doing}

Overview. There are a variety of ethical approaches that incorporate the concept of justice. Reynolds (2014) posited that ethics in counselling are fluid and living responses to the social contexts that clients inhabit. Reynolds (2012) proposed a framework for an ethic of justice-doing — informed by feminist, queer, and anarchist theory, decolonizing practices, and critical trans politics - which places justice at the centre of practice. This is not a principles-based approach, nor does it focus centrally on individual rights or relationships. Justice-doing is a commitment to an ethic of enacting justice and to contesting injustice by "tak[ing] on oppression and injustices on all fronts, at the intersections of our power and privileges, where we have power and where we are oppressed” (Richardson \& Reynolds, 2012, p. 6). This requires workers to act swiftly to address social inequities, resist replicating dominance, and be open to critique.

There are six guiding intentions of justice-doing: centering ethics, doing solidarity, fostering collective sustainability, addressing power, critically engaging with language, and structuring safety (Reynolds, 2012). Centering ethics in the work is essential to sustainability in the face of ongoing violations of our ethics by societal injustices. Focusing on collaboration, recognizing that people take many different paths, and embracing the role of an imperfect ally are key in doing solidarity. Fostering collective sustainability requires pushing back against individualism and working collectively alongside clients to combat unjust structures in ways that promote dignity, safety, and belonging. Addressing power takes the form of active resistance to oppression, and includes being accountable for more than just one's personal acts. Critically engaging with language means recognizing that language is not neutral, and can be used as a tool to obscure the realities of people's experiences of violence and oppression. Finally, safety must be structured through intentionally creating conditions that form a "safe enough" environment for 
International Journal of Child, Youth and Family Studies (2017) 8(1): 74-96

clients. This is accomplished through "a complex analysis of power, moral courage, compassion, and critical supervision” (Reynolds, 2012, p. 28).

Kai (age 14) is a very social and artistically talented youth who is involved in drama, music, art, and many other school and community activities. She seems to know everyone, and is well liked by her peers and the adults in her life. Kai says she is always "reinventing" her image, with various clothes, make-up, and hairstyles. Sometimes she presents as quite masculine and other times as highly feminine.

June, a CYC worker at the community centre where Kai attends a lot of arts programs, has noticed a change in her recently. She is more withdrawn and gets agitated easily. June has tried to talk with her on a few occasions, but Kai has been resistant. One day Kai asks to talk, and tells June that she has been feeling anxious and depressed. She says she has always felt like a boy, but is trying to live up to everyone's expectations of her as a girl. In tears, Kai says she only feels comfortable when presenting as a male, and finds it increasingly hard to "act like a girl”. She says she knows her parents love her, but they frequently make anti-gay and anti-trans comments when she dresses like a guy.

Kai denies feeling suicidal, but does confirm symptoms of anxiety and depression, and that she has started drinking and smoking marijuana and cigarettes to cope. She has seen a therapist in the past, but that therapist has moved away. Kai asks if June can help her find a new therapist who can help her change her feelings of being a boy, so that she feels like a girl. Kai thinks this might be the only way to solve her problems.

Analysis. June is committed to acting ethically through justice-doing. She has confirmed that Kai is struggling with peer and family relationships, and with mental health issues and with substance use. The root of much of this struggle appears to be the gender-based stigma and oppression Kai is experiencing. Kai is asking for help to conform to societal and family expectations, as she is unable to cope with the external and internalized oppression she is facing. June, who is aware that the reparative therapy Kai is requesting is considered harmful and unethical to practice, must determine how to ethically respond to Kai's request.

June has already observed the first intention for justice-doing — she is committed to centering ethics in her work. June does not identify as trans and recognizes that she should expand her knowledge of and work alongside trans communities to become a better ally. For June, doing solidarity means striving to develop greater understanding of the many paths that may lead to wellbeing. She ponders whether, as Kai believes, reparative therapy really could be a step along the path to wellness. However, as she listens to the voices of those who have suffered as a result 
of this practice and examines the evidence that trans youth are unlikely to change their gender, she understands why reparative therapy has been deemed a harmful practice.

June begins to shift her focus away from the issue of referring to reparative therapy to the reasons why it exists. There is injustice in the stigma that often surrounds trans communities and leads to the erosion of dignity, safety, and belonging. June needs to contribute to collective sustainability by joining alongside trans communities to fight these injustices, potentially through adopting a gender affirmative approach to care and advocating to create a world where diverse gender identities and expressions are affirmed rather than pathologized and oppressed.

Standing up for the right to freely identify and express gender and working to ensure policies and systems are in place to support youth and parents are forms of active resistance to power and oppression. Refusing to refer Kai to the harmful practice of reparative therapy is also a form of active resistance, one that can be enacted with love and care. While June has not been a direct perpetrator of overt oppression against Kai or other trans people, justice-doing mandates that she is accountable for more than her own acts. In this case, it means dispelling the myth that reparative therapy is an effective, acceptable, and ethical intervention.

Critically engaging with language can help June to see how trans people's experiences with violence, power, and oppression can be obscured from view. We live in a highly gendered society, one that strongly promotes a binary view of gender and the idea that gender should be congruent with sex assigned at birth. Though perceptions are changing and strides are being made in terms of trans rights, gendered structures are entrenched in our institutions and language. For example: "Boys line up here and girls line up over there."; "Girls don't play with trucks, those are for boys."; and "You can't have long hair and be a boy!". The messages are pervasive and strong, and they are internalized by all of us. Language can also be used to create a culture of blame and shame: "If he didn't choose to dress like that, he wouldn't get bullied." Constantly combating unnecessarily gendered language and working to uncover how our language promotes and obscures violence against trans communities is a necessary practice in justice-doing.

Returning to Kai’s experience, June knows that Kai has heard and internalized messages that "being trans is not okay". The impacts of systemic oppression, comments from her parents, and internalized stigma have likely contributed to Kai's feeling that it is her gender that needs to change. This is perhaps the most significant manifestation of these injustices - undermining Kai's sense of safety within herself. Kai's ultimate gender path is unknown. She may later identify as a woman, a man, neither, or both. June knows she must act to create a space that is safe enough for Kai to explore her gender. She also needs to create the safety necessary to address the conflict evident in Kai's relationship with her parents, and to help the parents understand how Kai is impacted by their actions.

Resolution. June is examining how power has impacted Kai and must summon the moral courage needed to support Kai in the face of this oppression. She will draw on compassion and 
seek supervision, but act without delay. June will talk with Kai about a referral to a therapist who can support her in her exploration of gender. With compassion and honesty, she will work to create a "safe enough" space to discuss how reparative therapy can be harmful, and that she cannot refer Kai to the kind of therapist she has requested. June will journey alongside Kai and her parents to learn how she can best support each of them on their journeys. She will also work with trans communities to address injustices that impact trans youth, continually remaining open to critique so that she may better her allyship.

\section{Discussion}

Scenarios highlighting issues that may arise in practice with trans youth and their families have been analyzed based on four ethical approaches: bioethics, rights-based ethics, relational ethics, and justice-doing. Each ethical approach varies in terms of what it brings to the forefront. The following section is a discussion of the strengths each framework possesses as well as the issues it does not address.

Bioethics is a parsimonious, widely used approach. Its strength lies in the straightforward application of the four foundational principles of autonomy, beneficence, non-maleficence, and justice. This approach, however, can be seen as paternalistic and lacking both cultural relevance and explicit collaboration with clients, families, and communities. It does not actively promote integration of ethical thinking into everyday practice, but rather frames certain situations as ethical dilemmas to be resolved by providers who possess power to make decisions.

Examining a situation from a rights-based perspective can assist in generating an understanding of the complexities of multifaceted issues. Dilemmas often emerge when rights and responsibilities come into conflict, and employing a rights-based approach can directly address this. A key strength of rights-based frameworks is their alignment with established, international rights of youth such as privacy, freedom from harm, self-determination, and non-discrimination. It should be noted that these frameworks lack a relational component and do not necessarily address cultural or larger societal influences on the experiences of clients.

Relational ethics is based in language and dialogue. These are fluid and living, not static universal truths or rights. Relational ethics is malleable and able to take environment, culture, stigma, and marginalization into account. It brings to the forefront respect for differences, family, community, diversity, and collaboration. However, relational ethics is open to interpretation by individual practitioners and therefore to the blind spots each inevitably has. It contrasts with bioethics and rights-based ethics in its focus on ethics being constantly enacted in all relationships, rather than a paradigm in which particular dilemmas are extracted to solve with a structured framework.

Finally, justice-doing follows the premise that ethics always needs to be at the centre of practice. It places the practitioner and client alongside one another and attempts to reduce paternalism. Justice-doing can be seen as more challenging to enact than other approaches, but it 
addresses complexities that other frameworks do not include. It goes beyond individual interactions and isolated dilemmas to a larger context, examining intersecting oppressions and the institutional and societal injustices that impact clients. It demands commitment and, for many individuals and institutions, can require a paradigm shift in how practice is approached.

No ethical approach exists in isolation. The various approaches influence one another and overlap and evolve over time. Professional codes of ethics, such as the Standards of Practice of North American Child \& Youth Care Professionals (Association for Child \& Youth Care Practice, 1995), often draw upon a range of ethical traditions, leaving it up to each practitioner to decide how they will enact ethics in their practice. This has the potential to result in inconsistent practices; however, this issue can be mitigated through the integration of sound evidence, critical thinking, and explicit argumentation into ethical practice. Additionally, practitioners can benefit from seeking out education and reflecting upon their own gender privilege in order to better meet the needs of trans youth. Intersections of oppression are also relevant to this discussion, as privileged positions can obscure from view the experiences of those with multiple intersecting oppressions (e.g., those related to gender, race, age, and class). Mindfulness of one's own privileges and worldview is important in this work, as is awareness of when information, education, and supervision are needed to help navigate ethically challenging situations.

This paper has primarily focused on issues of gender and how they intersect with age in the ethical care of trans youth and their families. Future work in CYC ethics is needed to directly address intersecting oppressions - such as gender, race, age, and class - and to examine diverse cultural perspectives on supporting trans youth. The approaches presented here have drawn on various philosophical and disciplinary traditions; however, there are many other ethical approaches that may also be applied with trans youth and their families in CYC practice, social work, counselling, and education.

\section{Conclusion}

Mac, Aiden, Jade, and Kai all face challenges connected to unjust stigma and marginalization. The knowledge that family support and access to gender affirming medical care are important factors in the wellbeing of trans youth guides ethical decision-making with this population. The practice of supporting trans youth and their families can be messy. Considering the ethics of our actions is crucial.

Despite their grounding in diverse ethical approaches, the analyses presented in this paper have consistently led to three imperatives: providing support and affirmation for trans youth; supporting families to support their youth; and fighting injustice where it impedes these goals. We must stand up for those whose voices are least heard and least well understood. This may take us out of our comfort zone, require that we relinquish some previously held assumptions, and call on us to act as imperfect allies (Reynolds, 2012). However, it is our individual actions that can 
International Journal of Child, Youth and Family Studies (2017) 8(1): 74-96

determine whether rights are upheld or violated, whether trans youth are supported or oppressed, and whether or not society becomes more just. 
International Journal of Child, Youth and Family Studies (2017) 8(1): 74-96

\section{References}

Antommaria, A. H. M. (2014). Pubertal suppression and professional obligations: May a pediatric endocrinologist refuse to treat an adolescent with gender dysphoria? The American Journal of Bioethics, 14(1), 43-46. doi:10.1080/15265161.2014.862408

Association for Child \& Youth Care Practice. (1995). Standards of practice of North American Child \& Youth Care Professionals. College Station, TX: Child \& Youth Care Certification Board. Retrieved from http://cyccb.org/ethics/

Austin, W. J. (2008). Relational ethics. In L. M. Given (Ed.) The SAGE encyclopedia of qualitative methods (pp. 748-749). Thousand Oaks, CA: SAGE. doi:10.4135/9781412963909.n378

Baltieri, D. A., Prado Cortez, F. C., \& de Andrade, A. G. (2009). Ethical conflicts over the management of transsexual adolescents-report of two cases. The Journal of Sexual Medicine, 6(11), 3214-3220. doi:10.1111/j.1743-6109.2009.01409.x

Beauchamp, T. L., \& Childress, J. F. (2013). Principles of biomedical ethics (7th ed.). New York, NY: Oxford.

Bergum, V. (2013). Relational ethics for health care. In J. L. Storch, P. Rodney, \& R. Starzomski (Eds.), Toward a moral horizon: Nursing ethics for leadership and practice (2nd ed., pp. 127-142). Toronto, ON: Pearson.

Bernal, A. T., \& Coolhart, D. (2012). Treatment and ethical considerations with transgender children and youth in family therapy. Journal of Family Psychotherapy, 23, 287-303. doi:10.1080/08975353.2012.735594

British Columbia Teachers’ Federation. (2016). LGBTQ Policies and Regulations. Retrieved from http://bctf.ca/SocialJustice.aspx?id=17994

Canadian Association of Social Workers, \& Canadian Association of Social Work Educators. (9 January 2015). Joint statement on the affirmation of gender diverse children and youth. Retrieved from http://www.casw-acts.ca/en/joint-statement-affirmation-gender-diversechildren-and-youth

CBC News. (05 June 2015). LGBT conversion therapy ineffective and harmful, critics say: Ontario first province to ban the practice for LGBT youth. Retrieved from http://www.cbc.ca/news/canada/lgbt-conversion-therapy-ineffective-and-harmful-critics$\underline{\text { say-1.3101838 }}$ 
International Journal of Child, Youth and Family Studies (2017) 8(1): 74-96

Coleman, E., Bockting, W., Botzer, M., Cohen-Kettenis, P., DeCuypere, G., Feldman, J., ... Zucker, K. (2012). Standards of care for the health of transsexual, transgender, and gendernonconforming people (Ver. 7). International Journal of Transgenderism, 13(4), 165-232. doi:10.1080/15532739.2011.700873

de Vries, A. L. C., \& Cohen-Kettenis, P. T. (2012). Clinical management of gender dysphoria in children and adolescents: The Dutch approach. Journal of Homosexuality, 59(3), 301-320. doi:10.1080/00918369.2012.653300

de Vries, A. L. C., Cohen-Kettenis, P. T., \& Delemarre-van de Waal, H. (2006). Clinical management of gender dysphoria in adolescents. International Journal of Transgenderism, 9(3-4), 83-94. doi:10.1300/J485v09n03_04

de Vries, A. L. C., McGuire, J. K., Steensma, T. D., Wagennar, E. C. F., Doreleijers, A. H., \& Cohen-Kettenis, P. T. (2014). Young adult psychological outcomes after puberty suppression and gender reassignment. Pediatrics, 134(4). doi:10.1542/peds.2013-2958

Diekema, D. S., Mercurio, M. R., \& Adam, M. B. (2001). Preface. In D. S. Diekema, M. R. Mercurio, \& M. B. Adam (Eds.), Clinical ethics in pediatrics: A case-based textbook (xixiv). New York, NY: Cambridge University Press.

Ehrensaft, D. (2016). The gender creative child: Pathways for nurturing and supporting children who live outside gender boxes. New York, NY: The Experiment.

Giordano, S. (2007). Gender atypical organisation in children and adolescents: Ethico-legal issues and a proposal for new guidelines. The International Journal of Children's Rights, 15(3-4), 365-390. doi:10.1163/092755607X262793

Giordano, S. (2013). Children with gender identity disorder: A clinical, ethical, and legal analysis. New York, NY: Routledge.

Heath, M. (2012). On critical thinking. The International Journal of Narrative Therapy and Community Work, 4, 11-18.

Herman, J. L. (2013). Gendered restrooms and minority stress: The public regulation of gender and its impact on transgender people's lives. Journal of Public Management and Social Policy, 19(1), 65-80.

Hidalgo, M. A., Ehrensaft, D., Tishelman, A. C., Clark, L. F., Garofalo, R., Rosenthal, S. M., ... Olson, J. (2013). The gender affirmative model: What we know and what we aim to learn. Human Development, 56(5), 285-290. doi:10.1159/000355235

Holman, C. W., \& Goldberg, J. M. (2006). Ethical, legal, and psychosocial issues in care of transgender adolescents. International Journal of Transgenderism, 9(3), 95-110. doi:10.1300/J485v09n03_05 
International Journal of Child, Youth and Family Studies (2017) 8(1): 74-96

Khatchadourian, K., Amed, S., \& D. L. Metzger. (2014). Clinical management of youth with gender dysphoria in Vancouver. The Journal of Pediatrics, 164(4), 906-911. doi:10.1016/j.jpeds.2013.10.068

Kreukels, B. P. C., \& Cohen-Kettenis, P. T. (2011). Puberty suppression in gender identity disorder: The Amsterdam experience. Nature Reviews Endocrinology, 7, 466-472. doi:10.1038/nrendo.2011.78

London, L. (2008). What is a human-rights based approach to health and does it matter? Health and Human Rights Journal, 10(1), 56-80.

Milrod, C. (2014). How young is too young: Ethical concerns in genital surgery of the transgender MTF adolescent. Journal of Sexual Medicine, 11, 338-346. doi:10.1111/jsm.12387

New York State. (6 February 2016). Governor Cuomo announces executive actions banning coverage of conversion therapy. Albany, NY: Governor's Press Office. Retrieved from https://www.governor.ny.gov/news/governor-cuomo-announces-executive-actions-banningcoverage-conversion-therapy

Office of the United Nations High Commissioner for Human Rights. (2008). The right to health: Fact sheet no. 31. Retrieved from http://www.ohchr.org/Documents/Publications/Factsheet31.pdf

Olson, J., Forbes, C., \& Belzer, M. (2011). Management of the transgender adolescent. Archives of Pediatrics \& Adolescent Medicine, 165(2), 171-176. doi:10.1001/archpediatrics.2010.275

Olson, K. R., Durwood, L., DeMeules, M., \& McLaughlin, K. A. (2016). Mental health of transgender children who are supported in their identities. Pediatrics, 137(3), 2015-3223. doi:10.1542/peds.2015-3223

Osmo, R., \& Landau, R. (2001). The need for explicit argumentation in ethical decision-making in social work. Social Work Education, 20(4), 483-492. doi:10.1080/02615470120064723

Peel, M. (2005). Human rights and medical ethics. Journal of the Royal Society of Medicine, 98(4), 171-173. Retrieved from https://www.ncbi.nlm.nih.gov/pmc/articles/PMC1079446/

Pollard, C. L. (2015). What is the right thing to do: Use of a relational ethic framework to guide clinical decision-making. International Journal of Caring Sciences, 8(2), 362-368.

Provincial Health Services Authority. (2016). Transgender health information program: Social. Retrieved from http://transhealth.phsa.ca/social-transition-options 
International Journal of Child, Youth and Family Studies (2017) 8(1): 74-96

Reynolds, V. (2012). An ethical stance for justice-doing in community work and therapy. Journal of Systemic Therapies, 31(4), 18-33.

Reynolds, V. (2014). Centering ethics in group supervision: Fostering cultures of critique and structuring safety. The International Journal of Narrative Therapy and Community Work, 1, $1-13$.

Richardson, C., \& Reynolds, V. (2012). “Here we are, amazingly alive”: Holding ourselves together with an ethic of social justice in community work. International Journal of Child, Youth and Family Studies, 1, 1-19. doi:10.18357/ijcyfs31201210471

Roen, K. (2016). The body as a site of gender-related distress: Ethical considerations for gender variant youth in clinical settings. Journal of Homosexuality, 63(3), 306-322. doi:10.1080/00918369.2016.1124688

Ryan, C., Russell, S. T., Huebner, D., Diaz, R., \& Sanchez, J. (2010). Family acceptance in adolescence and the health of LGBT young adults. Journal of Child and Adolescent Psychiatric Nursing, 23(4), 205-213. doi:10.1111/j.1744-6171.2010.00246.x

Stein, E. (2012). Commentary on the treatment of gender variant and gender dysphoric children and adolescents: Common themes and ethical reflections. Journal of Homosexuality, 59(3), 480-500. doi:10.1080/00918369.2012.653316

Swann, S. K., \& Herbert, S. E. (2009). Ethical issues in the mental health treatment of trans adolescents. In G. P. Mallon (Ed.), Social work practice with transgender and gender variant youth (2nd ed., 38-52). New York, NY: Routledge.

Taylor, C., \& Peter, T., with McMinn, T. L., Elliot, T., Beldom, S., Ferry, A., Gross, Z., Paquin, S., \& Schachter, K. (2011). Every class in every school: The first national climate survey on homophobia, biphobia, and transphobia in Canadian schools. Final report. Toronto, ON: Egale Canada Human Rights Trust. Retrieved from http://egale.ca/wpcontent/uploads/2011/05/EgaleFinalReport-web.pdf

Travers, R., Bauer, G., Pyne, J., Bradley, K., Gale, L., \& Papadimitriou, M. (2012). Impacts of strong parental support for trans youth: A report for the Children's Aid Society of Toronto and Delisle Youth Services. Toronto, ON: TransPulse. Retrieved from http://transpulseproject.ca/wp-content/uploads/2012/10/Impacts-of-Strong-ParentalSupport-for-Trans-Youth-vFINAL.pdf

United Nations General Assembly. (1989). Convention on the rights of the child. Retrieved from http://www.ohchr.org/Documents/ProfessionalInterest/crc.pdf 
International Journal of Child, Youth and Family Studies (2017) 8(1): 74-96

Vancouver School Board. (2014). Policy manual ACB-R-1: Sexual orientation and gender identities. Vancouver, BC: Author. Retrieved from https://www.vsb.bc.ca/districtpolicy/acb-r-1-sexual-orientation-and-gender-identities

Veale, J., Saewyc, E., Frohard-Dourlent, H., Dobson, S., Clark, B., \& the Canadian Trans Youth Health Survey Research Group. (2015). Being safe, being me: Results of the Canadian trans youth health survey. Vancouver, BC: Stigma and Resilience Among Vulnerable Youth Centre, School of Nursing, University of British Columbia. Retrieved from http://www.saravyc.ubc.ca/2015/05/05/being-safe-being-me-results-of-the-canadian-transyouth-health-survey/

Vrouenraets, L. J. J. J., Fredriks, A. M., Hannema, S. E., Cohen-Kettenis, P. T., \& de Vries, M. C. (2015). Early medical treatment of children and adolescents with gender dysphoria: An empirical ethical study. The Journal of Adolescent Health, 57(4), 367-373.

Wells, K., Roberts, G., \& Allan, C. (2012). Supporting transgender and transsexual students in K-12 schools: A guide for educators. Ottawa, ON: Canadian Teachers Federation.

World Health Organization. (2006). Constitution of the World Health Organization (45th ed. supplement). Retrieved from http://www.who.int/governance/eb/who_constitution_en.pdf 